\title{
Capital social no município de Inhambane em Moçambique e sua relação com a agricultura e o turismo
}

\author{
Social capital in the municipality of Inhambane in Mozambique and its \\ relationship with agriculture and tourism
}

Alice Alfredo Zua Nunes', Luís João Artur "

\begin{abstract}
RESUMO
O capital social tem sido largamente apresentado como fator fundamental para dinamizar o desenvolvimento local porque o mesmo funciona com base em redes sociais marcadas por confiança, reciprocidade e ajuda mútua, acredita-se que ele pode, muito rapidamente, ser mobilizado e usado para o bem-estar social local. Visto deste modo, o presente artigo teve como objetivo a análise do capital social no Município de Inhambane (MI), localizado na província de Inhambane, Sul de Moçambique, e a sua relação com a agricultura e o turismo que são praticados neste local. Para o alcance deste objetivo fez-se um inquérito a 163 agregados familiares em 11 bairros do município e entrevistas semi-estruturadas a representantes dos mesmos, das associações e de instituições governamentais. Com base nisso foi feito o cálculo do índice do capital social do Ml. Em seguida, aplicou-se a regressão logística para se perceber se existia alguma relação entre a participação em associação ou rede com as características demográficas como sexo, idade, bairro, nível de escolaridade. Os resultados do estudo mostram um índice de capital social médio, afetado sobretudo pelo fraco associativismo. A ligação entre agricultura e turismo é fraca devido a fatores sobretudo organizacionais, de quantidade e qualidade de produtos agrícolas e, de fraco incentivo pelos orgãos competentes. Os resultados mostram ainda que as mulheres, as pessoas pouco escolarizadas, os jovens e os agregados familiares vivendo fora da zona de influência direta do turismo tendem a estabelecer mais redes sociais do que os homens, as pessoas mais escolarizadas, os mais velhos e as pessoas que vivem em zonas turísticas. No geral reina um capital social de ligação, havendo assim a necessidade de dinamizar o capital social de ponte e de conexão.
\end{abstract}

Palavras-chave: Associações agrícolas, agricultura e turismo, capital social, desenvolvimento das comunidades

\section{ABSTRACT}

Social capital has been presented as a fundamental factor for local development. Given the fact that it operates on the basis of trust, reciprocity and mutual support it is perceived to be readily available and easy to apply. Under this background, the present paper aimed to understand the role that social capital plays for the development of the agricultural and tourism sector in the Inhambane municipality in Mozambique. For this endeavor, 163 households were interviewed using a survey and representatives from key institutions were interviewed using semi-structured interviews. A social capital index was produced and a logistic regression was

Docente no Departamento de Geografia desde 2010, formada em Desenvolvimento Rural e trabalha na área de Sistemas de Informação Geográfica e tem como área de pesquisa o capital social das comunidades na Universidade Eduardo Mondlane, Faculdade de Letras e Ciências Sociais, Departamento de Geografia, MoçambiqueE-mail zuaalice@gmail.com. ORCID:

"Docente no departamento de Engenharia Florestal e Investigador. Doutorado em Sociologia de Desastres, mestre em Sociologia do Desenvolvimento na Universidade Eduardo Mondlane, Faculdade de Agronomia e Engenharia Florestal, Moçambique. E-mail. lartur2000@yahoo.com ORCID 
run to provide key parameters leading to participation of households in associations. Findings shows an average social capital index ( 0.7 out of 1 ) affected mainly by poor performance of associations. It also shows limited interaction between agriculture and tourism due mainly to organizational aspects, quality and quantity of the agricultural products and limited incentives from the government. Overall, women, less educated people, youth and people living outside the tourism zone are more likely to participate in associations and develop social capital. The paper concludes that in the municipality of Inhambane there is a really need to develop bonding and connecting capitals.

Keywords: Agricultural association, agriculture and tourism, social capital, communities' development.

\section{INTRODUÇÃO}

Estudos mais recentes ressaltam que a participação da comunidade é fundamental para o alcance do desenvolvimento. Esta participação deverá, no entanto, ser feita de forma estruturada para que se produza ou fortaleça um capital social capaz de gerar dinâmicas internas e ligações externas indispensáveis para o desenvolvimento.

O capital social está ligado às características da vida social, suas redes, normas e confiança que permitem aos participantes atuar juntos de forma acentuada para alcançar objetivos comuns (PUTNAM, 1993). Desta maneira, o capital social está ligado a coletividade e esta, conduz à ações coordenadas que beneficiam não apenas um indivíduo mas a comunidade inteira. Visto desta forma, Bilert et al., (2011) afirmam que em termos de desenvolvimento, quanto mais os sujeitos se conscientizam que as mudanças na sua localidade dependem de esforços comuns direcionados de acordo com seus interesses coletivos, mais eles promovem o desenvolvimento local e direcionam os processos para uma dimensão que protagoniza transformações no espaço local.

O capital social difere dos outros por ser inerente a estrutura das relações entre as pessoas e por meio das pessoas, que por sua vez, ajuda a estabelecer obrigações entre os atores sociais, cria redes de confiança, abre canais de comunicação e impõe sanções para certos comportamentos sociais ( COLEMAN,1988). Analisar o capital social representa uma forma lógica de perceber como as sociedades se estruturam e como esta estruturação impacta no bem-estar das pessoas de forma individual assim como no seu coletivo (PORTES, 1998). As sociedades são uma construção social dinâmica que reflete a movimentação, ao longo do tempo, de normas, valores, crenças, comportamentos e práticas que, com este dinamismo ligam e desligam os seres humanos de diferentes maneiras com resultados 
muitas vezes imprecisos e profícuos. Estudar o capital social mostra-se assim relevante por poder trazer à luz os comportamentos que norteiam as sociedades num determinado espaço e tempo e as implicações disso para o seu bem-estar (COSTA,2007).

O presente artigo tem como objetivo analisar o papel do capital social no Município de Inhambane, na dinamização das atividades agrícolas e de turismo presentes no local. $\mathrm{O}$ capital social é simultaneamente um elemento dinamizador e beneficiário de ligações. É de se esperar que a existência dum forte capital social numa determinada comunidade seja um elemento dinamizador das atividade agrícolas e do turismo no local, da mesma forma que o desenvolvimento destas atividades obrigue a que as comunidades se organizem e fortaleçam as suas redes e a confiança entre os membros de modo a tirarem melhores benefícios derivado do desenvolvimento das mesmas. A avaliação do papel do capital social na dinamização de atividades e do bem-estar social local é ainda incipiente em Moçambique daí que, o presente trabalho ajudará a melhor perceber como os níveis de organização social local impactam no bem-estar e, deste modo, ajudar o governo e outros atores a melhor desenharem as suas estratégias de intervenção no país dum modo geral e no município de Inhambane de forma particular.

O Município de Inhambane é a capital administrativa da província de Inhambane, à Sul de Moçambique e localiza-se à cerca de $500 \mathrm{Km}$ a Norte da capital de Moçambique, cidade de Maputo. Este município, de aproximadamente 192 km²., é limitado ao Norte e a Oeste pela Oceano índico através da Baía de Inhambane, ao Sul pelo Distrito de Jangamo através do rio Guiúa e a Este igualmente pelo Oceano İndico na latitude $23^{\circ} 50^{\prime}$ Sul e longitude 35 e 30' (CMCl, 2009), veja a figura 1.

Com uma população estimada pelo INE (2017) em 79.724 habitantes (53,3\% do sexo femenino), distribuída por 23 bairros, a cidade de Inhambane é a segunda mais antiga cidade de Moçambique seguindo da Ilha de Moçambique que foi a primeira capital do país durante a penetração colonial. Reza a história que, na sua passagem por esse município, o explorador colonial Vasco da Gama fora bem recebido pelos nativos tendo por isso, batizado Inhambane de Terra de Boa Gente, nome com a qual a cidade de Inhambane continua até hoje conhecida. 
As principais atividades econômicas são a agricultura, a pesca e turismo. Os produtos agrícolas mais destacados são a mandioca, milho, hortaliças e feijões. O turismo de sol e praia que se pratica ao longo de quase todo o ano, sobretudo na região norte deste município, representa uma grande fonte de receitas. Gota (2018) destaca a existência de pouco mais de 150 estabelecimentos turísticos que recebem turistas sobretudo da África do Sul com uma estadia média de 12 dias. Kajale \& Artur (2020) notaram que a taxa de pobreza (de consumo) neste município é de $40 \%$, sendo que os bairros mais a Norte (nas zonas turísticas) apresentam maiores taxas de pobreza e maior desigualdade social medida pelo índice de Gini.

\section{Figura 1. Localização da área de estudo. Fonte: elaborado pelos autores}

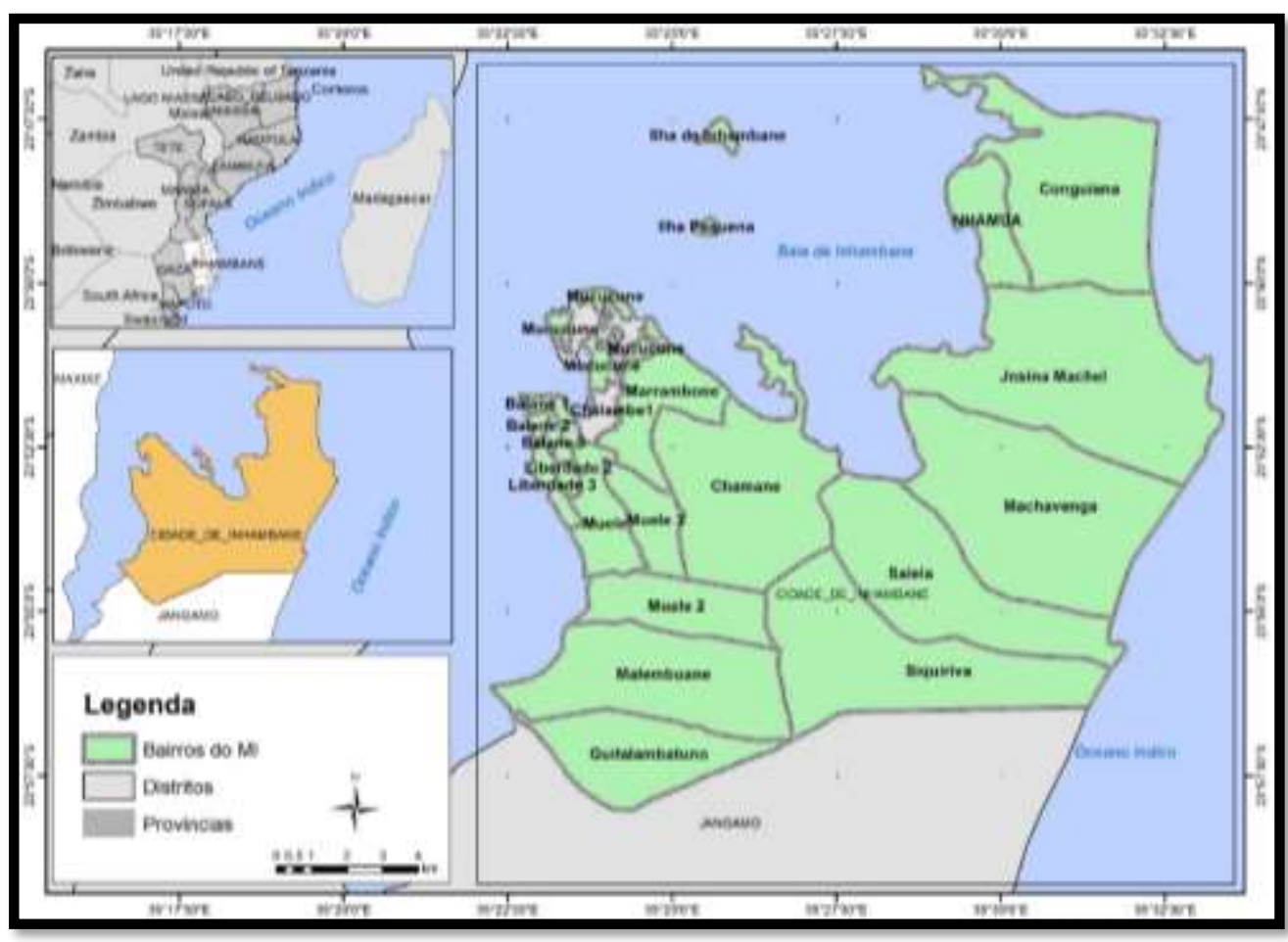

O artigo está estruturado em 5 partes: a primeira de introdução incluiu a problematização, os objetivos e uma breve descrição da área de estudo. A segunda apresenta o quadro teórico à volta do capital social com enfoque sobre o estado da mesma em Moçambique. A terceira descreve a metodologia usada para a recolha e análise de dados. A quarta apresenta e discute os resultados. Finalmente, a quinta parte apresenta as considerações finais. 


\section{CONCEITO DE CAPITAL SOCIAL}

Não existe um conceito único sobre o capital social, no entanto, dos vários conceitos existentes, pode-se encontrar algo comum: capital social refere-se as relações sociais que são criadas por meio das pessoas. O tratamento sobre capital social é antigo como as próprias relações sociais. Autores como Bourdeau, Coleman, Putnam, Abromovay, Baker foram grandes precursores mundiais desta discussão, os quais iluminaram a nossa forma de pensar e abordar as relacões sociais e a construção da mesma.

Bourdieu (1986) define o capital social como o conjunto de recursos potenciais ou reais resultantes do fato de pertencer a muito tempo ou de modo mais institucionalizado às redes de relações de conhecimento e reconhecimento mútuo. A rede destas relações são produto de estratégias de investimento individuais ou coletivas, conscientes ou inconscientes, com objetivo de estabelecer ou reproduzir as relações sociais, sejam elas individuais ou instituticionais.

Coleman (1990), por sua vez, define o capital social pela sua função, como formas de estrutura social que facilitam as ações dos indivíduos que se encontram dentro desta sociedade. Por outro lado, Putnam (2000) menciona que o capital social são aspectos da organização social, tais como redes, normas e confiança que facilitam a coordenação para benefícios mútuos. Dum modo similar, com pequenas variações, diferentes autores foram

destilando e cristalizando o capital social naquilo que se tornou nosso atual conhecimento. A tabela abaixo sumariza grandes pensamentos à volta do capital social a partir de diferentes autores. 
Tabela 1: principais conceitos do capital social

\begin{tabular}{|l|l|}
\hline Conceitos & Autores \\
\hline $\begin{array}{l}\text { Capital social é o agregado do atual ou potencial recurso que é reunido para } \\
\text { possessão de uma durável rede de relações mais ou menos institucionalizadas de } \\
\text { mútuo conhecimento ou identificação. }\end{array}$ & Bourdieu (1985) \\
\hline $\begin{array}{l}\text { Capital social é uma variedade de entidades com dois elementos em comum, os } \\
\text { quais consistem de algum aspecto de estruturas sociais e facilitam evidentes ações } \\
\text { de atores (pessoas ou corporações) com a estrutura. }\end{array}$ & Coleman (1988) \\
\hline $\begin{array}{l}\text { Capital social é um recurso que deriva de atores de específicas estruturas sociais, } \\
\text { sendo usado para perseguir seus interesses, é criado pelas trocas nas relações entre } \\
\text { atores. }\end{array}$ & Baker (1990) \\
\hline $\begin{array}{l}\text { Capital social é o conjunto de elementos das estruturas sociais que afetam as } \\
\text { relações entre pessoas e são inputs ou argumentos da produção e/ou utilidade } \\
\text { funcional. }\end{array}$ & Schiff (1992) \\
\hline $\begin{array}{l}\text { Capital social é como amigos, colegas e, de forma mais geral, contatos diretos de } \\
\text { quem você recebe oportunidades para usar seu capital humano e financeiro. }\end{array}$ & Burt (1992) \\
\hline $\begin{array}{l}\text { Capital social são traços da vida social - redes de contatos, normas e confiança - } \\
\text { que possibilitam aos participantes agirem juntos mais efetivamente para perseguir } \\
\text { objetivos em comum. }\end{array}$ & Putnam (1995) \\
\hline
\end{tabular}

Fonte: Adaptado de Portes (1998); Walker (2008) citados por Tondolo et al., (2012)

Teoricamente o capital social tem uma natureza multidimensional. Banco Mundial (1997) citado por Aguiar e Neto (2014) subdivide o capital social em três dimensões: o capital social de ligação que basicamente referem-se a ligações de pessoas que se conhecem tais como membros a família, amigos próximos e vizinhos; o capital social de ponte que se estabelece entre pessoas não próximas, mas de status sociais comparáveis; finalmente, o capital social de conexão que se estabelece entre pessoas de estratos sociais diferenciados incluindo os tomadores de decisão.

Em resumo e com base nas diferentes definições acima, pode-se deduzir que o capital social cria redes sociais que são alimentadas pela confiança entre as pessoas cujo benefício é, em geral, o bem comum. Visto desta forma, o capital social pode dinamizar uma sociedade e fomentar ações que de outra maneira não seriam possíveis. Assim visto, postulamos que o mesmo pode, de alguma forma, dinamizar as atividades praticadas pela população com o enfoque específico na agricultura e no turismo no Município de Inhambane. Abromovay (2000) nota que o elevado nível do capital social na comunidade pode garantir, sustentar e criar associações agrícolas mais coesas. Putnam (1993, citado por FREY, 2003) revela que 
uma alta densidade de associações e a existência de relações sociais de reciprocidade são as principais premissas de uma democracia vital e de um engajamento cívico efetivo.

Aliando os dois, pode-se claramente notar que o capital social pode ser um fator importante para dinamizar processos produtivos, ao mesmo tempo em que, funciona como uma ferramenta vital para o engajamento cívico, democratização e prestação de contas. Estes fatores não apenas garantem o caráter democrático da sociedade civil, mas também determinam a performance dos governos locais e de suas instituições. Frey (2003) refere que a organização social sustentada por uma rede de associações civis e por formas de cooperação baseadas em regras compartilhadas e em confiança recíproca se mostrou fundamental para um bom desempenho das instituições e da eficiência da sociedade e de sua economia. O mesmo pode ser aplicado quando se trata de associações agrícolas ou de turismo. Quanto maior for o número de associações e o grau de envolvimento dos seus membros, pode-se garantir uma comunidade mais eficiente e dinâmica.

\subsection{Capital social e agricultura}

A agricultura, especialmente a 'tradicional', é uma atividade de risco, pois nem todo investimento tem o seu retorno dependendo das condições climáticas. Desde modo, muitos camponeses não conseguem firmar-se economicamente em virtude do ambiente físico e agroecológico em que estão inseridos. Por outro lado, a produção agrícola nestas economias 'rudimentares' está bastante entrelançada com o contexto social que os vincula ao mercado para a obtenção de insumos, para a comercialização de seus produtos, para a obtenção de financiamentos e o acesso à informação. Ou seja, quanto maior for a sua rede, maior é a possibilidade de reduzir os riscos associados a produção agrícola e integrar-se no mercado (ABRAMOWAY, 2012, citado por ALMEIDA, 2014).

Umas das formas de tentar alargar essas redes e permitir maior inserção dos produtores no mercado têm sido em parte, dinamizando as associações agrícolas. Estas associações são grupos de produtores que de forma estruturada, trabalham de forma coletiva nas machambas (campos de produção agrícola com área inferior a 0.5 hectares), procuram conjuntamente comprar insumos e vender seus excedentes e facilitar o acesso a 
serviços financeiros e de extensão. Devido às vantagens de agregar pessoas reduzindo custos de transação e de prestação de serviços, o associativismo tem sido bastante difundido em Moçambique como em outras partes do mundo. O associativismo passou a ser assim, uma forma de criar ou dinamizar o capital social que, como visto anteriormente, traz múltiplas vantagens para o desenvolvimento local.

Frey (2003) foi bastante condescendente em relação as associações. Ele refere que o aprofundamento de todos os tipos de associações em uma dada sociedade representa o seu estoque de confiança e reciprocidade, isto é, seu estoque de capital social. Destaca ainda que elas representam formas básicas da vida social pois são essenciais para o estabelecimento de normas de reciprocidade e padrões comuns para a promoção de confiança social, interpessoal e para o crescimento do engajamento ć́vico. Porque o associativismo aparece como elemento crucial no desenvolvimento do capital social, o presente artigo irá dedicar um grande realce ao funcionamento do associativismo no município de Inhambane.

\subsection{Capital social, agricultura e turismo}

A relação entre o capital social, a atividade agrícola e a turística é complexa (CHOENKWAN et al., 2016) de tal forma que é falacioso abordar na plenitude, as formas pelas quais se manifesta essa relação, mesmo que teoricamente a agricultura esteja relacionada com a turística e as duas com as redes sociais que se estabelecem para o desenvolvimento de ambas.

A atividade agrícola pode estar ligada à turística de forma direta, indireta ou passiva. Nota-se uma agricultura que é caracterizada por ter uma ligação direta com o setor de turismo se a atividade agrícola estiver associada ao mercado turístico, ou seja, a atividade agrícola constitui per se, um produto turístico. Ligações indiretas indicam que a agricultura constitui um setor preponderante ao turismo ao ser fonte de matéria-prima para o desenvolvimento harmonioso da atividade turística no destino, através de fornecimento de produtos agrícolas. Por último, existe uma ligação passiva se estas duas atividades compartilharem somente a coexistência geográfica (LUN et al., 2016). Em uma perspectiva 
de análise, com enfoque na relação turismo na agricultura, percebe-se também que a atividade turística pode possuir efeito negativo em relação à agrícola, se entre essas atividades existe antagonismo sobre os recursos preponderantes, como é o caso da água, terra e mão-de-obra ou outros recursos relacionados e existentes nas zonas rurais (SCHNEIDER e FIALHO, 2000).

De forma geral, a relação entre agricultura e turismo é majoritariamente desencadeada mediante o subsetor de restauração que envolve os hotéis, restaurantes, bares e outros tipos de estabelecimentos que lidam com a alimentação do turista no destino. Assim, os agricultores familiares frequentemente fornecem produtos agrícolas a estes estabelecimentos quer diretamente ou mediante intermediários (GURUNG, 2012, citado por GOTA, 2018).

Neste contexto, o fortalecimento do capital social na agricultura familiar poderá de alguma forma, dinamizar o setor de turismo, ou seja, melhorar o abastecimento dos produtos alimentares às entidades turísticas. Além disso, o capital social poderá fazer com que as famílias praticantes da agricultura possam expandir as suas atividades para além da agricultura passando a fornecer outros produtos e serviços demandados pelos turistas tais como produtos de artesanato, turismo cultural, gastronômico, entre outros. Neste sentido, o capital social pode servir de duplo propósito aumentando a oferta de produtos agrícolas bem como a oferta de produtos turísticos.

\subsection{Capital social no contexto de Moçambique}

A discussão sobre o capital social no desenvolvimento local é ainda embrionário em Moçambique. Incipiente é ainda a discussão do capital social usando uma mensuração quantitativa e uma abordagem mista qualitativa e quantitativa de análise de dados. Referências de trabalho sobre redes sociais incluem fundamentalmente o trabalho de Mungoi (2010) que, usando uma abordagem qualitativa, olhou para a interação dos atores no vale do Zambeze, zona central de Moçambique, tendo concluído que foram estabelecidas ligações sociais entre atores locais e externos, que permitiu que a região fosse ao longo do 
tempo receptora de cadeia de decisões e implementação de projetos e empreendimentos concebidos fora ou longe daí.

Hassamo (2015) analisou o papel capital social das comunidades rurais do distrito de Inharrime para o funcionamento dos comitês de gestão de água. Com efeito, o mesmo orientou-se por uma questão central - até que ponto o Capital Social das comunidades da área de estudo está suficientemente desenvolvido para assegurar o pleno funcionamento dos comitês de gestão de água. O autor concluiu que as comunidades não têm o seu Capital Social amplamente fortalecido, de modo a poder funcionar como um ativo social favorável à participação massiva das comunidades nas questões cívicas que exigem o seu envolvimento incluindo a gestão de recursos hídricos. Como resultado, nota-se com frequência avarias das bombas de água e fraca reparação das mesmas.

Artur (2011) analisou como as relações sociais afetam respostas à desastres em Moçambique, tendo concluído que a necessidade de manter relações sociais no curto e longo prazo, determina em grande medida o momento de evacuação durante as cheias, o local para onde evacuar ou a permanência nestes locais.

Mardade (2014) analisou o papel da participação comunitária na construção do capital social entre os membros da associação de regadores de Mafuaine na província de Maputo. Ele concluiu que a participação em atividades coletivas é determinada pela expectativa de obter benefícios que deriva em parte, da experiência vivida pelos membros atuais da associação sobre as vantagens que os membros anteriores tinham por fazer parte da mesma. Ele notou ainda que as relações sociais são desenvolvidas em forma de ajuda mútua e solidariedade entre os membros, que inclui o apoio na abertura das machambas, na lavoura, na partilha de insumos agrícolas e explicações sobre técnicas de produção.

Muito recentemente, Tsandzane (2018) analisou até que ponto os jovens estão usando as redes sociais (virtuais) para aumentar o seu capital social tendo concluído que os jovens permanecem como os "conectados abandonados", que representam, na sua globalidade, a face do desemprego urbano e a precariedade social e econômica em Moçambique. Esses mesmos jovens estão nas cidades, mas também nas áreas rurais e usam as redes para "reclamar sem mostrar o rosto" e "sem sair da rede". A esta situação acrescenta-se a individualização das ações que dizem respeito à juventude moçambicana, a 
falta de uma agenda partilhada sobre os problemas, às necessidades desta camada social e em último, as desigualdades sociais, econômicas e políticas entre jovens da mesma cidade fazem com que haja fraca mobilização.

No geral, apesar de ainda incipiente, nota-se uma expansão tanto quantitativa como qualitativa do conhecimento sobre redes sociais e capital social em Moçambique. Isto deriva igualmente do reconhecimento cada vez maior do papel das ciências sociais na resolução dos problemas do país.

\section{MATERIAIS E MÉTODOS}

O presente artigo é baseado em dados coletados tanto por métodos qualitativos assim quanto por quantitativos. A recolha de dados aconteceu em 11 dos 23 bairros do Município de Inhambane (MI). A seleção dos bairros foi feita com base na qualificação do Conselho Municipal, Vereação de Agricultura e Turismo, que indicaram os bairros com predominância da atividade agrícola e de turismo que era o foco da pesquisa.

Para garantir uma amostra representativa da população do estudo e seguir o rigor técnico, fez- se o uso da equação abaixo (fórmula 1), pois a mesma é comumente usada por vários pesquisadores (FILHO et al. 2006; ISRAEL, 2013; BARTLET, et al. 2001 citado por GOTA, 2018) para a determinação do tamanho da amostra. O presente estudo usou a amostragem probabilista estratificada para a seleção dos sujeitos de pesquisa. A identificação dos agregados a serem inquiridos fez-se da seguinte forma:

Fórmula 1: Cálculo do tamanho da amostra

$$
n 0=\frac{1}{\mathrm{E} 2} \quad n=\frac{N * n 0}{N+n 0}
$$

Onde:

n0 (aproximação do tamanho da amostra);

E2 (erro amostral admitido); o erro aceitável foi de $5 \%$ ou seja 0,05 .

n (tamanho da amostra); N (população da pesquisa) 
Dados do campo indicaram que até 2012, o MI possuía 65.149 habitantes que representam 13.030 agregados familiares (Nhabomba, 2013). Mediante esses dados e a fórmula 1, fez-se o cálculo do tamanho da amostra dos agregados que foram alvo de inquérito, como descrito a seguir.

$$
n 0=\frac{1}{(0,05) 2}=>\frac{1}{0,0025}=400 \quad \mathrm{n}=\frac{13030 * 400}{13030+400}=>=\frac{5212000}{13430}=388
$$

Deste tamanho de amostra total, selecionou-se apenas os 11 bairros indicados pelo Município. E desta seleção, resultaram em 163 agregados que foram alvos do presente estudo. Quanto às associações, fez-se um censo de todas as associações existentes no Ml e aquelas que estiveram disponíveis para a entrevista totalizaram 22 associações.

\subsection{Análise da Regressão}

A presente pesquisa fez uso da regressão logística para inferir fatores determinantes para participar em associações e, deste modo, dinamizar o capital social. A regressão logística é usada para analisar a probabilidade de um evento estar a favor ou não da variável dependente, que neste caso é categórica.

A equação da regressão logística é apresentada da seguinte forma:

$$
\begin{aligned}
& \eta_{i}=\log \left(\frac{p_{i}}{1-p_{i}}\right)=\sum_{k=0}^{K} \beta_{k} x_{i k} \quad \text { Onde a probabilidade é dada por: } \\
& p_{i}=\frac{\exp \left(\sum_{k=0}^{K} \beta_{k} x_{i k}\right)}{1+\exp \left(\sum_{k=0}^{K} \beta_{k} x_{i k}\right)} \text { O modelo da regressão logística é dada por: } \\
& \ln \frac{p}{1-p}=\beta_{0}+\beta_{1} x_{1}+\ldots+\beta_{q} x_{q}
\end{aligned}
$$

De acordo com os dados do trabalho, o objetivo da regressão logística é encontrar as variáveis que explicam a participação ou não do agregado numa associação ou rede social. Deste modo, a hipótese a ser testada foi a seguinte: 
Ho=A participação em alguma associação ou rede está altamente relacionada com o sexo, a idade, nível de escolaridade e o bairro onde o agregado familiar (AF) vive.

Variável dependente: Pertencer a associação ( $0=$ não pertence $1=$ Pertence (binomial) Variáveis independente: Idade, sexo, nível de escolaridade, bairro.

\section{ANÁLISE QUALITATIVA}

A análise qualitativa foi constituída por entrevistas semi-estruturadas feitas aos presidentes das associações agrícolas, um grupo de agricultores, presidentes de associações de outras entidades sociais ou de prestação de serviços na comunidade como a ORAM, MEGAFAUNA, ALMA, AJABA, grupo de vendedores de lembranças turísticas na praia da Barra e do Tofo. A identificação destas associações foi através do método de bola de neve, onde se perguntava aos entrevistados se conheciam outras associações que atuavam nas mesmas áreas, em especial os secretários dos bairros que após a entrevista indicavam vários grupos que atuavam no seu bairro.

A determinação dos agregados familiares (pessoas que vivem na mesma casa e com alguma relação de parentesco) a serem inquiridos baseou-se em alguns casos pela forma de repetição $(K=N / n)$, onde:

$\mathrm{N}$ é o tamanho total dos agregados familiares e n é o número total de amostras. Baseando-se nesta fórmula o fator de repetição foi de 33. Chegava-se em cada bairro, questionava-se o número de quarteirões e então selecionava-se o primeiro agregado aleatoriamente e os restantes usando o fator de repetição. Nos casos em que o número dos Afs era inferior a soma do fator de repetição, procurava-se escolher uma familia em cada quarteirão e a escolha era aleatória.

\subsection{Análise quantitativa}

De modo a se perceber melhor os níveis de capital social existentes no MI, fez-se uma tabulação dos dados com os principais indicadores. Com base nestes dados foi possível ter 
uma idéia genérica sobre a tendência do capital social na área de estudo. A análise dos dados obedeceu à duas fases:

Análise descritiva dos dados (apresentação das frequências, médias, percentagens) de modo a perceber a tendência dos dados e,

Análise da diferença entre vários grupos (sexo, idade, nível de escolaridade).

\subsection{Mensuração do capital social}

Para a construção desta pesquisa, foram adotados os conceitos abordados por Putnam (1993), que olha para o capital social como aspectos da organização social tais como redes, normas e confiança que facilitam as coordenações mútuas, e também a abordagem de Coleman (1990), que olha para o capital social como forma de estrutura social que facilita as ações entre os indivíduos que participam dentro desta estrutura. Analisou-se no MI, as redes sociais, normas e confiança ali existentes, a estrutura social atual e sua relação com desenvolvimento. Foram adaptados os indicadores apresentados por Ribeiro et al.(2012), Castilhos (2002), e Banco Mundial (2003) para responder aos objetivos do estudo (vide a quadro 1).

\section{Quadro 1. Indicadores do Capital social}

\begin{tabular}{|c|c|}
\hline Categorias & Parâmetros \\
\hline \multicolumn{2}{|l|}{ Grupos e redes } \\
\hline $\begin{array}{l}\text { Números de associações/redes que o } \\
\text { AF pertence }\end{array}$ & $\begin{array}{l}\text { Quanto maior for o número de associações/redes, maior } \\
\text { possibilidade de existência do CS maior }\end{array}$ \\
\hline $\begin{array}{l}\text { Frequência de participação nas } \\
\text { associações/redes }\end{array}$ & $\begin{array}{l}\text { Quanto maior for a frequência de participação, maior será a } \\
\text { existência de CS }\end{array}$ \\
\hline Beneficios & $\begin{array}{l}\text { Quanto maior forem os beneficios da associação/rede, maior } \\
\text { possibilidade de CS }\end{array}$ \\
\hline Disposição de ajudar o grupo/rede & $\begin{array}{l}\text { Quanto maior for a disposição de ajudar, maior possibilidade } \\
\text { de CS }\end{array}$ \\
\hline \multicolumn{2}{|l|}{ Confiança e solidariedade } \\
\hline Número de amigos & $\begin{array}{l}\text { Quanto maior for o número de amigos, maior a possibilidade } \\
\text { de CS }\end{array}$ \\
\hline Nível de confiança & $\begin{array}{l}\text { Quanto maior for o nível de confiança nas pessoas, maior } \\
\text { será a existência do CS }\end{array}$ \\
\hline Disposição de ajudar os vizinhos & $\begin{array}{l}\text { Quanto maior for a disposição de ajudar outros, maior } \\
\text { possibilidade de CS }\end{array}$ \\
\hline Contar com ajuda de outros & $\begin{array}{l}\text { Quanto mais provável confiar na ajuda de outros, maior será } \\
\text { a existência do CS }\end{array}$ \\
\hline
\end{tabular}




\begin{tabular}{|l|l|}
\hline Categorias & Parâmetros \\
\hline $\begin{array}{l}\text { Disposição de trabalhar em prol do } \\
\text { bairro }\end{array}$ & $\begin{array}{l}\text { Quanto maior for a disposição de trabalhar a favor do bairro, } \\
\text { maior será a possibilidade do CS }\end{array}$ \\
\hline Ação coletiva e cooperação & $\begin{array}{l}\text { Quanto maior o engajamento dos membros da comunidade } \\
\text { em ações que promovam o desenvolvimento coletivo, maior a } \\
\text { possibilidade de existência de CS. }\end{array}$ \\
\hline Participação em atividade comum & $\begin{array}{l}\text { Quanto menor for a proibição de participação nas atividades, } \\
\text { maior será a existência do CS }\end{array}$ \\
\hline Proibição de participar em atividades & $\begin{array}{l}\text { Quanto mais distantes forem as pessoas, menor será a } \\
\text { existência do CS }\end{array}$ \\
\hline Proximidade das pessoas & Quanto maior forem as diferenças, menor a existência de CS. \\
\hline Níveis de diferenças & $\begin{array}{l}\text { Quanto maior forem os problemas decorrentes das } \\
\text { diferenças, menor a possibilidade de existência de CS. }\end{array}$ \\
\hline Problemas decorrentes das diferenças de \\
\hline Nível de Conflito & $\begin{array}{l}\text { Quanto maior a existência de conflitos entre os membros de } \\
\text { uma comunidade, menor será a possibilidade de existência de } \\
\text { CS. }\end{array}$ \\
\hline Nível de sociabilidade & $\begin{array}{l}\text { Quanto maior o nível de sociabilidae, maior será a existência } \\
\text { do CS }\end{array}$ \\
\hline
\end{tabular}

Fonte: adaptado pelos autores de Barreto et al., (2005)

Para o cálculo do índice do capital social, seguiu-se a metodologia usada por Ribeiro et.al, (2012), conforme apresentado na figura 2. O autor começou por calcular o índice do capital social, usando indicadores como participação em atividades externas, os laços de amizade, a disposição em ajudar, as diferenças individuais, o espírito de união entre as pessoas, entre outros. A seguir, mostrou a contribuição de cada indicador para o índice do capital social. Para a análise, foram assumidos alguns valores para cada tipo de resposta. Para cada afirmação foi atribuído valor dois, para cada negação, valor zero; e para cada possibilidade remota, valor um.

Figura 2: Fórmula para o cálculo do índice de capital social.

$$
I C S=\frac{1}{n} \sum_{j=1}^{n}\left[\frac{\sum_{i=1}^{m} \sum E i j}{\sum_{i=1}^{m} \sum \text { Emáxi }}\right]
$$

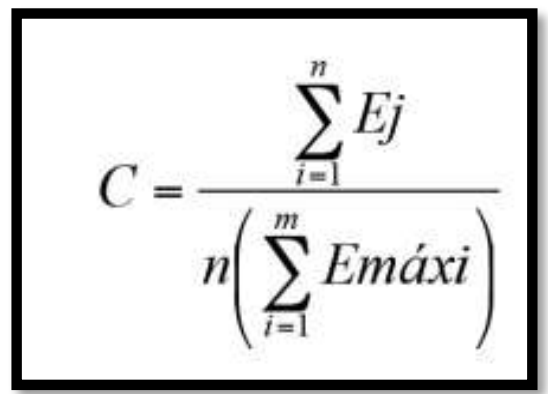

Fonte: Ribeiro et.al, (2012) 
Onde, ICS = Índice de Capital Social; Eij = escore do i-ésimo indicador, alcançado pelo j-ésimo produtor; Emáx $\mathrm{i}=$ escore máximo atingível pelo indicador $\mathrm{i} ; \mathrm{i}=1, \ldots, \mathrm{m}$ número de indicadores; $\mathrm{j}=1$, ..., n número de produtores; e $\mathrm{Ci}=$ contribuição do indicador i no ICS do grupo.

Quanto mais próximo de 1 o valor do índice do Capital Social (ICS), maior o nível de acumulação de capital social nas comunidades. Para a verificação do nível do capital social utilizou-se o seguinte critério, conforme mencionado por KHAN e SILVA (2002) citados por BARRETO et al.,(2005):

1. Baixo nível de acumulação de Capital Social $\quad 0<\mathrm{ICS} \leq 0,5$

2. Médio nível de acumulação de Capital Social $\quad 0,5<\mid \mathrm{ICS} \leq 0,8$

3. Alto nível de acumulação de Capital Social $\quad 0,8<\mathrm{ICS} \leq 1$

\section{RESULTADOS E DISCUSSÃO}

\subsection{Relação entre a participação em associações ou redes com fatores demográficos}

Aplicou-se a regressão logística para saber se a participação em alguma associação ou rede está altamente relacionada com o sexo, a idade, nível de escolaridade e a localização.

Tabela 2. Resultados da regressão logística

Variáveis na Equação

\begin{tabular}{|ll|l|l|l|l|l|l|}
\hline & \multicolumn{1}{|c|}{ B } & S.E. & Wald & df & \multicolumn{1}{c|}{ Sig. } & Exp(B) \\
\hline \multirow{2}{*}{$1^{\circ}$} & Genero_Dummy(1) & $-1,683$ & 428 & 15,434 & 1 &, 000 &, 186 \\
& Escolaridade_Dummy &,- 140 &, 276 &, 257 & 1 &, 612 &, 869 \\
Passo & Bairro_Dummy & & & 6,739 & 2 &, 034 & \\
& Bairro_Dummy(1) &,- 082 &, 476 &, 029 & 1 &, 864 &, 922 \\
& Bairro_Dummy(2) &, 911 &, 451 & 4,085 & 1 &, 043 & 2,488 \\
& Idade &, 030 &, 014 & 4,248 & 1 &, 039 &, 971 \\
& Constante & 2,042 & 1,111 & 3,382 & 1 &, 066 & 7,708 \\
\hline
\end{tabular}

a. Variavéis que entraram no passo 1: Genero_Dummy, Escolaridade_Dummy, Bairro_Dummy, Idade.

Fonte: acervo particular dos autores

\subsubsection{Variáveis independentes:}


Sexo/gênero ( $0=$ Mulher; 1 =Homem)

Idade

Escolaridade $(0=$ sem escolaridade; 1 = Primário; $2=$ Secundário; $3=$ Superior; $4=$ Ensino Técnico)

Bairro ( 1 = Norte (Conguiana, Nhamua e Josina Machel) $2=$ Sul(Liberdade, Chalambe, Balane e Marrambone); $0=$ Centro (Chemane, Salela, Sequiriva e Malembuane).

5.1.2 Modelo logístico

$\log \left(\frac{\pi}{1}-\pi\right)=\alpha+B 1 X 1+B 2 X 2+B 3 X 3+B 4 X 4+B 5 X 5$

$\log \left(\frac{\pi}{1}-\pi\right)=2.042-0.030$ Idade -1.683 Sexo -0.140 Escolaridade -0.082 Bairro

Norte + 0.911 Bairro Sul

Interpretação do modelo logístico

Coeficientes

O logaritmo de Odds de pertencer ou não a uma associação ou rede social é igual a 2.042 para pessoas com valor zero no gênero (mulher), zero na escolaridade e zero no bairro (bairros do centro). A idade diminui o log Odds de pertencer a associação por um fator de 0.030, controlando pelo gênero, escolaridade e bairro. Ser mulher ou homem diminui o log odds de pertencer à associação por um fator de 1.683 controlando pela idade, escolaridade e bairro. O nível de escolaridade diminui o log odds de pertencer a associação em $\mathbf{0 . 1 4 0}$ controlando pela idade, sexo e bairro. Estar em outros bairros versos estar no bairro do Norte diminui o log odds de pertencer a associação ou rede social em $\mathbf{0 . 0 8 2}$ controlando pela idade, sexo e escolaridade. Estar em outros bairros versos estar no bairro do Sul, aumenta o log odds de pertencer a uma associação ou rede em 0,911 controlando pela idade, sexo e escolaridade.

Interpretação em termos de odds ratio: $\operatorname{Exp}(B): e^{\beta}$

$\operatorname{Exp}(\mathbf{B})=0.971$ o aumento da idade diminui a probabilidade da pessoa pertencer a uma associação em 0.971 ou seja (2,9\%), controlando pela sexo, escolaridade e bairro. Ou seja, os jovens tem maior probabilidade de pertencer a uma associação ou rede. 
$\operatorname{Exp}(\mathbf{B})=0.186$ Comparado ao sexo feminino, ser do sexo masculino diminui a probabilidade da pessoa de pertencer a associação em 0,186 vezes (81,4\%), controlando pela idade, escolaridade e bairro. Ou seja, as mulheres têm maior probabilidade de pertencer a uma associação ou rede.

$\operatorname{Exp}(\mathbf{B})=0.869$ o aumento do nível de escolaridade diminui a probabilidade da pessoa pertencer a associação em 0.869 (13,1\%), controlando pela idade, sexo e bairro. Ou seja, as pessoas mais estudadas tendem a não fazer parte das associações.

$\operatorname{Exp}(\mathbf{B})=0.922$ Ser do bairro Norte diminui a probabilidade da pessoa pertencer a associação em 0.922 vezes (7,8\%), controlando o sexo, idade e o nível de escolaridade. Ou seja, as pessoas do bairro Norte tendem a se associar menos.

$\operatorname{Exp}(\mathbf{B})=\mathbf{2 , 4 8 8}$ Ser do bairro Sul, aumenta a probabilidade da pessoa de pertencer a associação em 2,488 (148,8\%). Ou seja, as pessoas do bairro Sul tendem a se associar mais.

O gênero tem maior efeito (Maior wald $=15.434$ ) e é significativo $(P$-value $=.0, P<0,05)$

Visto que o $\mathrm{P}$-value $<0,05$, pode-se concluir que o gênero tem um efeito significativo na probabilidade da pessoa de pertencer a uma associação ou rede social.

O mesmo para o bairro Sul, tem efeito maior ( wald $=6,739$ ) e é significativo ( $P$ value $=0,0334, \mathrm{P}<0,05)$.

Visto que o $\mathrm{P}$-value $<0,05$, pode-se concluir que o bairro onde a pessoa vive tem um efeito significativo na probabilidade de ela pertencer a uma associação ou rede social.

A variável idade também tem um efeito maior (wald=4,248 e é significativo ( $P$ value $=0,039, P<0,05)$

Visto que o $\mathrm{P}$-value $<0,05$, então se conclui que a idade tem um efeito significativo na probabilidade da pessoa pertencer a uma associação ou rede social.

\section{2 Índice do capital social}

O ICS do MI foi de 0,71 , ou seja, $0,5<\mathbf{0 , 7 1} \leq 0,8$, o que significa um médio nível de acumulação do Capital Social. Abaixo são apresentadas as tabelas com mais detalhes (tabela 3). 
Tabela 3. Índice de capital social do MI.

\begin{tabular}{|l|l|l|}
\hline Variàveis & ICS & $\%$ \\
\hline Pertence a alguma associação & 0,5123 & 10,4 \\
\hline $\begin{array}{l}\text { As pessoas no bairro ajudam umas as } \\
\text { outras }\end{array}$ & 0,9043 & 18,3 \\
\hline Confiança nos membros do governo & 0,5414 & 10,9 \\
\hline $\begin{array}{l}\text { Participação em alguma atividade coletiva } \\
\text { no bairro }\end{array}$ & 0,4444 & 9,0 \\
\hline Proximidade das pessoas & 0,8313 & 16,8 \\
\hline Diferença entre as pessoas & 0,8913 & 18,0 \\
\hline Bairro pacifico ou violento & 0,8210 & 16,6 \\
\hline Total & 4,9461 & 100 \\
\hline ICS Geral & $\mathbf{0 , 7 0 6 6}$ & \\
\hline
\end{tabular}

Fonte: organização dos autores

O índice com maior percentagem no CS é o relacionado ao indicador ou variável "as pessoas se ajudam uma as outras" e "pouca diferença entre as pessoas no bairro" ambas com 18\%, seguida da "proximidade das pessoas" (16,8\%), "bairro pacifico ou violento" (16,6\%). Os índices de menor peso foram de $9 \%$ associado ao indicador participação em alguma atividade coletiva no bairro, pertença a alguma associação (10,4\%) e confiança nos membros do governo (10,9\%). Estes indicadores contribuíram para o médio nível de acumulação de CS.

O baixo peso de o indicador pertencer ou não a alguma associação, ou rede, que na verdade é o capital social de ligação é corroborado com entrevistas feitas no campo. Por exemplo, a presidente da UCCI (União dos Camponeses da Cidade de Inhambane), dona Ana, disse o seguinte a respeito das associações agrícolasi:

"Um dos principais constrangimentos do funcionamento da UCCl é a falta de pagamento de quotas por parte das associações, o que compromete as outras actividades. As pessoas são membros da associação, mas não entendem efectivamente o que isso significa".

A presidente da associação agrícola de Marrambone, dona Ana Alexandre também comentou o seguinte: 
"As pessoas apenas aparecem para reuniões nas associações quando tem conhecimento de que algum apoio será dado, caso contrário, cada um está preocupado em trabalhar na sua machamba para seu sustento individual".

Comentários assim foram partilhado por quase $90 \%$ das associações. O mesmo acontece com a participação em outras redes sociais que não sejam agrícolas, há pouco conhecimento de associações informais no $\mathrm{Ml}$ em que os membros são ativos. As poucas associações que existem, não são fundadas pelos moradores dos bairros, mas sim por ONGs que visam financiar ou fomentar alguma atividade.

\subsection{Associações agrícolas versus capital social}

O Município de Inhambane tem atualmente (2020) 23 associações agrícolas, sendo apenas 5 legalizadas. O bairro Muelé apresenta maior número de associações (total de 8), seguido do bairro de Nhamua com 3 associações e os restantes bairros apresentam entre uma ou 2 associações. O trabalho de campo mostrou que não existe ligação direta entre a localização da associação e o bairro onde os membros residem. As associações estão localizadas nas zonas úmidas, nas baixas, e os membros não necessariamente pertencem aos mesmos bairros onde se localizam as zonas baixas. E, por este motivo, torna-se difícil relacionar a localização da associação com o nível de participação na atividade agrícola a nível dos bairros. No geral a prática de agricultura é feita por membros do agregado familiar, as vezes com apoio de vizinhos e amigos, o que revela que há uma tendência de uso do capital social de ligação.

Cada associação tem em média 20 membros. Nem todos os membros são ativos. De acordo com as entrevistas feitas aos presidentes das associações, há maior afluência de membros quando há informação de alguma ajuda da qual a associação irá se beneficiar.

Tabela 2. Lista de associações agrícolas.

\begin{tabular}{|l|l|l|l|l|l|}
\hline № & Associação & $\begin{array}{l}\text { Ano de } \\
\text { criação }\end{array}$ & $\begin{array}{l}\text { Localização } \\
\text { (Bairro) }\end{array}$ & Legalização & Membros \\
\hline 1 & 7 de Abril & 2003 & Siquiriva & Legalizada & 17 \\
\hline 2 & 24 de Julho & 2008 & Siquiriva & & 10 \\
\hline
\end{tabular}




\begin{tabular}{|l|l|l|l|l|l|}
\hline 3 & Vukane & 2015 & Salela & & 16 \\
\hline 4 & 15 de Outubro & 2006 & Salela & & 16 \\
\hline 5 & Bakula & 2012 & Chamane & & 22 \\
\hline 6 & Kuvuneca & 2010 & Chamane & & 35 \\
\hline 7 & Zonas Verdes & 1997 & Muele 1 & Legalizada & 22 \\
\hline 8 & 4 de Outubro & 2003 & Muele 1 & & 16 \\
\hline 9 & 7 de Setembro & & Muele 1 & S/Inf & \\
\hline 10 & Katalela & 2012 & Muele 1 & Legalizada & 25 \\
\hline 11 & Graça Machel & & Muele 1 & S/Inf & \\
\hline 12 & 3 de Fevereiro & 2014 & Muele 1 & & 19 \\
\hline 13 & 25 de Junho & 2008 & Muele 1 & Legalizada & 27 \\
\hline 14 & Irmãos Unidos de Quilongue & 2016 & Muele 3 & & 30 \\
\hline 15 & A hirimene & 2015 & Liberdade 2 & & 13 \\
\hline 16 & 8 de Março & 2008 & Chalambe 2 & & 13 \\
\hline 17 & Ngungulu & 2014 & Malembuana & & 22 \\
\hline 18 & Marrambone & 1997 & Nhamua & & 16 \\
\hline 19 & Conguiana & 1999 & Nhamua & Legalizada & 10 \\
\hline 20 & 1 de Maio & 2007 & Nhamua & & 5 \\
\hline 21 & Tsembeca & 2018 & Josina Machel & & 12 \\
\hline 22 & Pembane & 2017 & Josina Machel & & 49 \\
\hline 23 & Minenene & 2015 & Malembuana & & 64 \\
\hline
\end{tabular}

Fonte: organização dos autores

De modo geral, todas as associações dedicam-se a produção de hortaliças, como por exemplo: couve, alface, tomate, cebola, pimenta, beterraba, pepino. Não existe especialização na produção e deve-se sobretudo às pequenas dimensões das áreas de produção. As áreas são, em geral, inferiores a 0,5 hectares.

Dos 111 que praticam a atividade agrícola, apenas 12 responderam que pertence a alguma associação agrícola. O tempo médio em que fazem parte da associação é de 4 anos. Estes dados demonstram que há alguma durabilidade na permanência destes membros na associação, mas há pouca participação dos produtores em associações.

\subsubsection{Associação sob o ponto de vista local}


O desenvolvimento da agricultura neste município é dinamizado, sobretudo, pelo Conselho Municipal da Cidade de Inhambane $(\mathrm{CMCl})$, e os Serviços Distritais de Atividades Económicas (SDAE). Porém, o acesso a serviços e apoios por parte destas e outras entidades é feita, principalmente via associação. O SDAE por vezes tem prestado ajuda de forma individual, mas estes casos são raros. Deste modo, a intenção do agricultor ao se juntar a uma associação é ter, sobretudo, vantagens imediatas. Quando estas vantagens não se concretizam, em curto período, ele tende a abandonar a associação, ou seja, não participar das reuniões, falta ao pagamento de quotas e reduz a sua presença nos campos agrícolas. Devido a essa situação, verificada na maioria das associações agrícolas mencionadas acima, o conceito de associação no sentido de fortalecer o capital social parece-nos ainda ilusório. Era de se esperar que a criação de uma associação, seja ela formal ou não, deveria servir aos interesses comuns, ou seja, ter como objetivo satisfazer as necessidades coletivas e alcançar objetivos comuns por via de cooperação.

Dos 12 respondentes que pertencem a alguma associação agrícola, a maioria respondeu que um dos benefícios que sentia por fazer parte da associação é o apoio para aquisição de insumos agrícolas, pois por via de associações era mais fácil obter ajuda do SDAE e de outros parceiros que trazem e oferecem insumos agrícolas. Em geral nota-se um fraco dinamismo do associativismo agrícola no MI.

A situação verificada nesta área de estudo não é isolada. Como notado por autores referenciados anteriormente tais como Mardade (2014), Hassamo (2015) e também Pereira (2007, p. 6) citado por (Libombo et al., 2017) a maior parte das associações de nível local, em Moçambique, embora tenham sido criadas para resolver os problemas de seus membros e de suas comunidades, apresentam um funcionamento deficiente. As razões do fraco dinamismo do associativismo variam de região para região. No caso concreto do Ml, algumas razões apontadas para o funcionamento deficiente das associações incluem:

- Fraco conhecimento do funcionamento do associativismo;

- A gênese (externa) das associações;

- Falta de pagamento de quotas e jóias;

- Fracas lideranças;

- Forte dependência da ajuda externa para a obtenção insumos agrícolas; 
- Falta de mercado para a comercialização dos seus produtos;

- Em alguns casos, falta de área suficiente para a prática das suas atividades.

Existem, no entanto, algumas exceções. Em algumas como na associação Zonas Verdes há um sistema de obrigatoriedade em participar do cultivo da área comum, denominada área de demonstração. Existe uma área comum para as demonstrações de novas práticas de produção assistidas por um extensionista. Uma vez por semana, os membros trabalham nesta área e discutem a vida agrícola e social. Neste tipo de associações, quando os membros pagam as quotas, o valor é usado fundamentalmente para a compra de sementes a serem usadas no referido campo de demonstração. Porém, os membros podem igualmente se beneficiar, a preço bonificado ou a custo zero, da parte de sementes compradas.

\subsubsection{Relação entre agricultura e turismo no MI}

Apenas três (3) dos entrevistados, ou seja, oito porcento (8\%) dos que praticam a atividade ligada a agricultura é que comercializa os produtos para as instâncias turísticas, ou seja, quase não existe uma ligação entre a agricultura praticada pelos locais e o setor do turismo. Foram apontadas várias razões para o efeito que incluem:

A quantidade e qualidade do produto;

- A possibilidade de oferecer com regularidade;

- Falta de intermediação para ter acesso aos mercados;

- Fraca organização dos produtores e,

- Necessidade de venda imediata (nas machambas) para satisfazer igualmente necessidades imediatas.

\subsubsection{Associações de turismo}

Foram identificadas e inquiridas duas (2) associações ligadas a área do turismo no Município de Inhambane: AJABA (Associação Juvenil Aires Bonifácio Ali) e Quendimuca.

A AJABA, fundada em 2009, é constituída de pessoas que praticam atividades ligadas a escultura, pintura e fabrico de blocos (multifuncionais) que são vendidos na sua sede. Nos dias festivos, a associação é convidada para expor e vender os seus produtos em locais fora da sua sede e preparados para o evento. Assim como nas associações agrícolas, cada 
membro trabalha na sua obra e quando consegue comercializar, paga as quotas da associação e o valor devido ao uso do local e instrumentos da associação. Os membros são também oriundos de outras províncias do país, como Gaza e Maputo. Em entrevista com os responsáveis da associação foi referido que existem, no município, muitas pessoas que fazem esculturas e vendem nos mercados da cidade, mas estão interessados apenas em vender e não fazer parte de uma associação. Algumas estâncias turísticas (hotéis, restaurantes) aceitam expor as esculturas facilitando assim a comercialização dos produtos. No entanto, de maneira geral, existe pouco incentivo para a associação. Há dois anos era constante a existência de feiras (1 vez por mês) organizadas pelo MI para a exposição de produtos, porém atualmente cessou, dificultando deste modo a divulgação dos seus trabalhos. As feiras são organizadas apenas para os dias festivos, concretamente o dia do carnaval e da cidade.

Outra associação existente é a Quendimuca, que foi fundada em 2012. É formada por 10 membros (amigos). Cada membro tem a sua banca onde comercializa os seus produtos/esculturas. Apesar de receber convites do Conselho Municipal para participar em algumas feiras, os membros afirmaram que os ganhos reais são fracos nestas feiras pelo que preferem focar as suas vendas na praia do Tofo, onde se concentram muitos turistas.

Esta situação foi confirmada pelo departamento de Vereação do Conselho Municipal, onde a sra Raquel desta vereação, comentou que "atualmente as feiras ligadas ao turismo são feitas apenas nos dias festivos e são os operadores turísticos que apóiam estes eventos". Outros dias festivos, para além do dia da cidade e do carnaval, incluem os feriados nacionais, o festival da Barra, que ocorrem normalmente em Outubro/Novembro de cada ano, e o festival do fim de ano que ocorre em Dezembro. Existe também a feira de gastronomia, que é realizada uma vez por mês, especialmente no final do mês. De modo a garantir a participação da comunidade, o $\mathrm{CMCl}$ contata os secretários dos bairros, que por sua vez levam a informação à comunidade. Nota-se com isso, que não existe uma estrutura sólida de promoção das atividades ligadas ao turismo de modo a dinamizar esta prática. As pessoas ligam-se a comercialização de lembranças (vide a figura 3) para obter o sustento e uma vez alcançada, raramente procuram meios de engrandecer a atividade. 
Figura 3. Vendedores de lembranças turísticas na praia do Tofo. Fonte: acervo particular dos autores (Setembro de 2018)

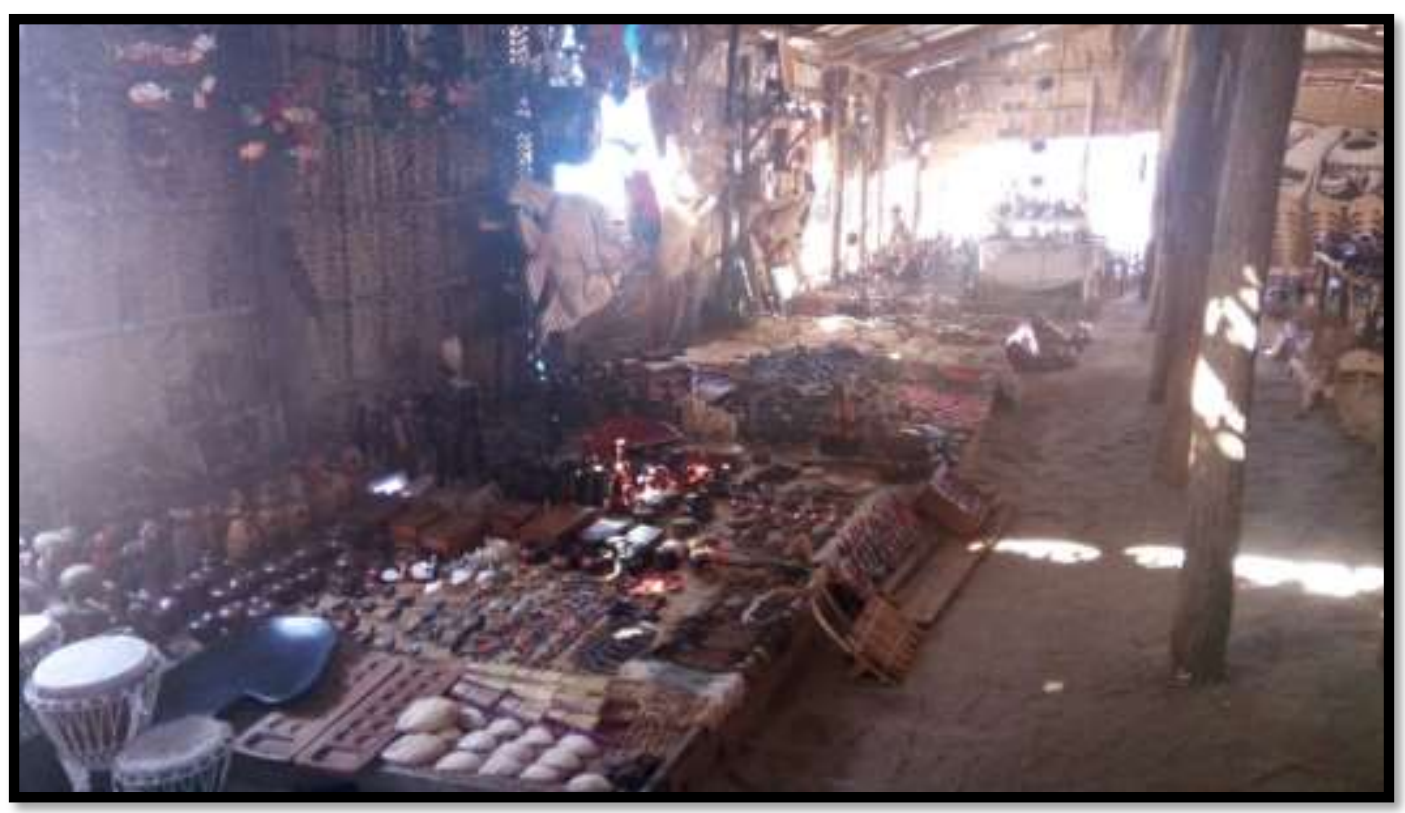

As praias são geralmente o local onde os vendedores querem de forma individual ou associada, se concentram para produzir e vender as suas obras de arte. A maior parte das pessoas está nesta atividade há mais de 10 anos. Alguns são fabricantes e outros apenas revendedores. Não existe um fluxo de comunicação sistemático que permite um maior dinamismo das atividades e a isso, se alia o fato de não existir uma plataforma que junta todos os atores que trabalham ou tem interesse no setor turístico.

Fornecedores de serviços turísticos foram unânimes em afirmar que precisam duma associação ou plataforma de ligação que poderia facilitar a obtenção de empréstimos e melhor circulação de informação e para os envolvidos nas obras de arte, a aquisição de um espaço definitivo para a venda dos seus produtos.

Pode-se notar pelas descrições feitas, que as pessoas querem, de alguma forma, estar ligadas ao turismo e acompanhar o desenvolvimento desta atividade, porém existe pouco apoio para o incentivo desta atividade ou pelo menos para aumentar a robustez da atividade. 


\section{CONSIDERAÇÕES FINAIS}

O presente artigo procurou avaliar o papel do capital social na dinamização das atividades agrícolas e de turismo no município de Inhambane. O mesmo visa alargar o debate em volta do assunto, agregando indicadores quantitativos de mensuração do capital social e procurando providenciar informação que ajude os tomadores de decisão, em particular do município de Inhambane, sobre como fortalecer este capital que tem efeitos no bem-estar social das comunidades locais. Os resultados do estudo revelaram que:

O associativismo tanto agrícola como no setor de turismo é ainda incipiente sendo marcado por encontros esporádicos e ligações não contínuas com o tempo. Os membros se reúnem, sobretudo em caso de recepção de bens ou para feiras de comercialização, isto torna difícil a dinamização do capital de ponte e de conexão.

A agricultura familiar assim como as atividades de turismo desenvolvidas pelos locais é majoritariamente realizada pelos membros da mesma família não havendo casos de contratação de mão-de-obra externa. No geral reina um capital social apenas de ligação. Há necessidade de um estudo mais aprofundado para se perceber como desenvolver outros tipos de capital social que seja o ímpeto do desenvolvimento, com enfoque para o capital social de conexão e de ponte.

Em geral, a ligação entre a agricultura e o turismo é fraca por razões que incluem quantidade e qualidade de produtos fornecidos pelos produtores locais, e, sobretudo pela fraca organização dos próprios produtores.

Em geral, as mulheres, os jovens, os indivíduos de baixa escolaridade e moradores fora das zonas turísticas localizadas na região norte do município tem maior probabilidade de se associarem e dinamizar o capital social.

\section{BIBLIOGRAFIA}

ABROMOVAY, R. O Capital Social do território: Repensando o Desenvolvimento Rural. Economia Aplicada, Vol. 4, No 2. 2000. 
AGUIAR, C. C., \& NETO, J. A. Análise da articulação entre o capital social e o associativismo: Uma abordagem colectivista. Oikos: Revista Brasileira de Economia Doméstica, Viçosa, v. 25, n.1, pp. 159-185. 2014.

ALBAGLI, S., \& MACIEL, M. L.Informação e Conhecimento na Inovação e no Desenvolvimento Local. Ci.Inf.vol.33, Nº 3 pp. 9-16. 2004.

ALMEIDA, R. Z. Associativismo na agricultura familiar e capital social: Uma alternativa para o desenvolvimento no meio rural brasileiro. ISSN 2316-266X, Volume. 2, No.3. pp. 385-402. 2014.

ANDRADE, E. d., \& CÂNDIDO, G. A. A Relação entre os Níveis de Capital Social e os Índices de Desenvolvimento Sustentável:Uma Análise Comparativa entre Municípios. In: XXXII ENCONTRO DA ANPAD/ Rio de Janeiro de 6 á 10, Setembro de 2008.

ARTUR, L. Continuities in crisis. Everyday practices of disaster response and climate change adaptation in Mozambique. PhD thesis. Wageningen University, The Netherlands. 2011

AZEVEDO, H. A., GOTA, P. J., \& ARTUR, L. J. Aproximações entre a Agricultura Famiiar e o Turismo no Município de Inhambane em Moçambique. Espaço e Tempo Midiáticos, Revista do grupode Pesquisa Mídias e Territorialidades Ameaçadas, Vol 1, nr. 1. JulhoDezembro de 2016.

BAQUERO, M. Construindo uma outra sociedade: $\mathbf{O}$ capital social na estruturação de uma cultura política participativa. Rev. Sociol. Polít., Curitiba, 21, pp. 83-108. Novembro de 2003.

BAQUERO, M., \& Cremonese, D. Capital social: Teoria e prática. Rio Grande do Sul: UNIJUÍ - Universidade Regional do Nordeste do Estado do Rio Grande do sul.2006.

BARRETO, R. C., KHAN, A. S., \& LIMA, P. V. Sustentabilidade dos assentamentos no Municipio de Caucaia. RER, Volume. 43, No. 02. pp. 225-247. Junho de 2005.

BILERT, V. S., PERONDI, M. A., PERREIRA, A. A., \& TERNOSKI, S. A Contribuição do Capital para o Desenvolvimento Local Sustentável. 2011. ISSN 1679-348X, Volume. 11, N.21, pp. 29-42.

BOURDIEU, P. The Forms of Capital. Em J. Richardson, Handbook of Theory of Research for the Sociology of Education. 1986. (pp. 241-258). Greenword Press.

CASTILHOS, D. S.Capital social e politicas públicas: Um estudo da linha infra-estrutura e serviço aos municipios do programa nacional de fortalecimento da agricultura familiar. 2002.173 p. (Programa de pós-graduaçao em desenvolvimento rural).

CONSELHO MUNICIPAL DA CIDADE DE INHAMBANE, C. M. Plano Estratégico do Municipio de Inhambane (2009-2019). 2009. Inhambane: $\mathrm{CMCl}$.

COLEMAN, J. S. Social Theory, Social Research and a Theory of Action. American Journal of Sociology. University of Chicago. 1986. Volume 91 Number 6, pp. 1309-.

COLEMAN, J. S. Social Capital in the Creation of Human Capital. American Journal of Sociology, University of Chicago, 1988. pp. 95-120. 
COLEMAN, J. S. Foundation of Social Theory. Em J. S. Coleman. London: The Belknap Press of Harvard University Press. Library of Congress Cataloging-in-Publication Data, 1990.

COLEMAN, J. S. The Vision of Fundation of Social Theory. Analyse \& Kritik 14, 1992. pp. 117-128.

COSTA, I. O capital social como instrumento para viabilização do desenvolvimento local e sustentável: Um estudo comparativo entre localidades participantes do pacto "Novo Cariri" dentro do programa SEBRAE-PB / Rede DLIS. 2007. Dissertação ( Mestre em Engenharia de Produção). Paraiba: João Pessoa.

COSTA, M. A.. Sinergia e capital social na construção de políticas sociais: A favela da Mangueira no Rio de Janeiro. Rev. Sociol. Polít., Curitiba, 21. pp. 147-163. Novembro de 2003.

DEFILIPPIS, J.The myth of social capital in community development. Housing Policy Debate - Hous Policy Debate 12., pp. 781-806. 2001.

FACCIN, K., Macke, J., \& GENARI, D. Mensuração do capital social nas redes colaborativas vitinícolas de Serra Gaúcha. o\&s - Salvador, v.20 - n.65, pp. 303-320. Abril/Junho de 2013.

FONTENELE, R. E., PEREIRA, M. P., \& SOUSA, A. M. Construção de um Modelo Explicativo sobre as Influências do Capital Social e do Empreendedor Colectivo nos níveis de Competitividade dos APLs. XXXV Encontro da ANPAD, Rio de Janeiro, 4 a 7 de Setembro, pp. 1-17. 2011. Obtido em 26 de Julho de 2017.

FREY, K. Capital Social, Comunidade e Democracia. Política e Sociedade, pp. 175-187. N.2 de Abril de 2003.

FUKUYAMA, F. The Imperative of State-Building. Journal of Democracy. 15, pp. 17-31. 10.1353/jod.2004.0026. 2004.

FURLANETTO, E. L. Instituições e desenvolvimento econômico: A importância do capital social. Curitiba: Rev. Social. Politica, Número Suplementar V. 16.pp 55-67. Agosto de 2008. GAYLE, V., \& LAMBERT, P. S. Logistic Regression Models in Sociological Research. pp. 1-44. April de 2011.

GIL, A. C. Como elaborar projectos de pesquisa. $4^{a}$ Edição. São Paulo: Editora Altlas S.A. 2002. GODOY, A. S. Pesquisa qualitativa - Tipos fundamentais. pp. 20-29. 1995.

GOTA, P. J. Agricultura Familiar e Turismo no Desenvolvimento das Zonas Rurais do Município de Inhambane. 2018. Maputo: Dissertação (Mestre em Desenvolvimento Rural), Universidade Eduardo Mondlane, FAEF.

GROOTAERT, C., \& BASTELAER VAN, T. Understanding and measuring Social capital: A multidisciplinary tool for pratitioners. Washingtonn D.C: Word Bank. 2002.

GROOTAERT, C., NARAYAN, D., JONES, V. N., \& WOOLCOCK, M. Questionário Integrado para Medir Capital Social (QI-MCS). Banco Mundial - Grupo Temático sobre Capital Social , pp. 1-66. 2003. 
HASSAMO, U.I.R. O Capital Social e o Seu Impacto no Funcionamento dos Comités de Gestão de Água Potável: O Caso das Comunidades Rurais do Distrito de Inharrime. 2015. Dissertação ( Mestre em Desenvolvimento Rural), Universidade Eduardo Mondlane, FAEF.

INSTITUTO NACIONAL DE ESTATISTICA. Recenseamento Geral da Populaçcão e Habitação.Indicadores Sócio-demográficos de Inhambane. 2017. INE.

KRISHNA, A., \& SHRADER, E. Social capital assessment tool. In: CONFERENCE ON SOCIAL CAPITAL AND POVERTY REDUCTION - The World Bank. 1999.

LIBOMBO, S. E., FERRANTE, V. L., DUVAL, H. C., \& LORENZO, H. C. Associações agrícolas e desenvolvimento local em Moçambique: perspectivas e desafios da Associação Livre de Mahubo. Revista Nera, Ano 20, N³8. ISSN 1806- 6755. pp. 132-150. 2017.

LIMA, R. J. Capital social e desenvolvimento regional: limites e possibilidades para a construção de novas institucionalidades. Revista Pós Ciências Sociais, Volume 7, N 13, pp. 83-100. 2010.

MARDADE, R.J.J. Papel da Participação Comunitária na Construção do Capital Social: O caso da Associação Regantes de Mafuaine no Distrito de Namaacha, província de Maputo. 2014. Monografia ( Licenciado em Sociologia), Universidade Eduardo Mondlane, FLCS.

MARTINS, H. H. Metodologia qualitativa de pesquisa. Universidade de São Paulo, São Paulo. 2004.

MAXLHAIEIE, J.P. \& CASTROGIOVANNI, A.C. Patrimônio Cultural e Turismo: Cenários sobre o Município de Inhambane, Moçambique. Revista Rosa dos Ventos-Turismo e Hospitalidade,6(3),pp.356-373,Jul-Set,2014. Disponível em <

https://core.ac.uk/download/pdf/236121514.pdf.> Acesso em 04 de Setembro de 2020.

MERTENS, F., TÁVORA, R., FONSECA, I. F., GRANDO, R., CASTRO, M., \& DEMEDA, K. Redes sociais, capital social e governança ambiental no territorio portal do Amazônia. Acta Amazónica, Vol. 41 (4), pp. 481-492. 2011.

MILANI, C. Teorias do Capital Social e Desenvolvimento Local: Lições a partir da Experiência de Pintadas (Bahia, Brasil). O \& S - V.11, pp. 95-113. 2004.

MUNGOI, C. desenvolvimento regional no vale do Zambeze, Moçambique em perspectiva. Revista de geopolítica, Ponta Grossa 1(1) 33-45. 2010

NHANOMBA, H. M. Levantamento, Análise e Prospectiva do Desporto no Conselho Municipal da Cidade de Inhambane-Moçcambique (2009-2012). Dissertação (Mestre em Gestão do Desportos). Lisboa: Universidade Técnica de Lisboa. 2013.

PASSADOR, J. L., SABES, J. J., FERREIRA, M. R., \& ZANATTA, O. A.. Capital Social e Desenvolvimento Rural Sustentável: Uma Abordagem Sistêmica da Verticalização da Agricultura Familiar.XII SIMPE- Bauru, SP, Brasil. Novembro de 2005.Disponível em < https://www.researchgate.net/publication/237826202>. Acesso em 01 de Outubro de 2018.

PENG, C.-Y. J. Logistic Regression (Chapter 46). Em D. Wyse, E. Smith, L. E. Suter, \& N. Selwyn, The BERA/SAGE Handbook of Educational Research (pp. 1-37). London : SAGE Publications. January de 2016. 
PORTES, A. Social Capital: Its Origin and Application in Modern Sociology. Annual Review of Sociology, Vol.24., pp. 1-24. 1998.

PUTNAM, R. Measure of Social Capital. 2000.

PUTNAM, R. D. What Make a Democracy Work. Em R. D. Putnam, Comunidade e Democracia - A experiência da Itália Moderna (pp. 101-107). Rio de Janeiro: Editora da Fundação Getúlio Vargas. 1993.

PUTNAM, R. D. "Bowling Alone: America's Declining Social Capital". Journal of Democracy, 65-78. 1995.

RIBEIRO, I. C., FERNANDO, E. A., \& RIBEIRO, H. M. Importancia do capital social para o desenvolvimento de uma Região. RURIS, Volume 6, № 1, pp. 15-43. Março de 2012.

RIGO, A. S., \& OLIVEIRA, R. R. Capital Social, Desenvolvimento Local e Stakeholders: o caso do projecto Urbe de Sebrae. Cadernos EBAPE, BR, Vol.6, N². 2008.

ROBERT D, P. Capital social, comunidade e democracia. pp. 175-187. 2001.

RODRIGUES, W., TEIXEIRA, M. C., \& SIVA, M. R. Capital social e desenvolvimento regional: O caso de Sudeste de Tocantis. REDES, Santa Cruz do Sul, , Volume 17, N¹, pp. 232-248. Abril de 2012.

SANTA, M. Comunidades Rurais de Baixo Rendimento em Pernambuco familiar no Estado do Paraná., pp. 61-74. Dezembro de 2017.

SOARES, A. P., \& ABREU, E. A. A Relação entre o Capital Social e o Desenvolvimento Local: o Caso das Comunidades Rurais de Baixo Rendimento em Pernambuco. In: CAMPO GRANDE, 25 A 28 DE JULHO, SOCIEDADE BRASILEIRA DE ECONOMIA, ADMINISTRAÇÃO E SOCIOLOGIA RURAL, 48 CONGRESSO. 2010.

STIGLITZ, J. E. Some Lessons From The East Asian Miracle,. The World Bank Research Observer, Volume 11, Issue 2. pp. 151-177. 1 de August de 1996. Disponível em <https://doi.org/10.1093/wbro/11.2.151> Acesso em 13 de Março de 2018.

TONDOLO, R. D., TONDOLO, V. A., \& BITENCOUR, C. C. Aspectos Metodológicos dos Estudos em Capital Social: Uma Análise dos Principais Periódicos Internacionais. $R$. eletr. estrat. neg., Florianópolis, v.5, n.1, pp. 110-136. Jan./Abr de 2012.

TSANDZANA, D. Juventude urbana e redes sociais em Moçambique. A participação política dos conectados desamparados. Revista Comunicação e Sociedade 34/2018. 2018

${ }^{i}$ As respostas dos entrevistados estão escritas no português de Moçambique. 